desired size. A coarse fibre may have a dozen or more, while such fibres as I find most useful have only two dark bands. Much finer ones exist, showing the colours of the first order with one dark band; and fibres so fine as to correspond to the white or even the gray of Newton's scale are easily produced.

Passing now from the most scientific test of the uniformity of these fibres, I shall next refer to one more homely. It is simply this: the coinmon garden spider, except when very young, cannot climb up one of the same size as the web on which she displays such activity. She is perfectly helpless, and slips down with a run. After vainly trying to make any headway, she finally puts her hands (or feet) into her mouth, and then tries again, with no better success. I may mention that a male of the same species is able to run up one of these with the greatest ease, a feat which may perhaps save the lives of a few of these unprotected creatures when quartz fibres are more common.

It is possible to make any quantity of very fine quartz fibre without a bow and arrow at all, by simply drawing out a rod of quartz over and over again in a strong oxyhydrogen jet. Then, if a stand of any sort has been placed a few feet in front of the jet, it will be found covcred with a maze of thread, of which the photograph on the screen represents a sample. This is hardly distinguishable from the web spun by this magnificent spider in corners of greenhouses and such places. By regulating the jet and the manipulation, anything from one of these stranded cables to a single ultra-microscope line may be developed.

And now that I have explained that these fibres have such valuable properties, it will no doubt be expected that I should perform some feat with their aid which, up to the present time, has been considered impossible, and this I intend to do.

Of all experiments the one which has most excited my admiration is the famous experiment of Cavendish, of which I have a full-size model before you. The object of this experiment is to weigh the earth by comparing directly the force with which it attracts things with that due to large masses of lead. As is shown by the model, any attraction which these large balls exert on the small ones will tend to deffect this 6-foot beam in one direction, and then if the balls are reversed in position the deflection will be in the other direction. Now, when it is considered how enormously greater the earth is than these balls, it will be evident that the attraction due to them must be in comparison excessively small. To make this evident the enormous apparatus you see had to be constructed, and then, using a fine torsion wire, a perfectly certain but small effect was produced. The experiment, however, could only be successfully carried out in cellars and underground places, because changes of temperature produced effects greater than those due to gravity. ${ }^{1}$

Now I have in a hole in the wall an instrument no bigger than a galvanometer, of which a model is on the table. 'The balls of the Cavendish apparatus, weighing several hundredweight each, are replaced by balls weighing $1 \frac{3}{4}$ pound only. The smaller balls of $\mathrm{I} \frac{3}{4}$ pound are replaced by little weights of 15 grains each. The 6 -foot beam is replaced by one that will swing round freely in a tube three-quarters of an inch in diameter. The beam is, of course, suspended by a quartz fibre. With this microscopic apparatus, not only is the very feeble attraction observable, but I can actuslly obtain an effect eighteen times as great as that given by the apparatus of Cavendish, and, what is more important, the accuracy of observation is enormously increased.

The light from a lamp passes through a telescope lens, and falls on the mirror of the instrument. It is reflected back to the table, and thence by a fixed mirror to the scale on the wall, where it comes to a focus. If the mirror on the table

I Dr. Lodge has been able, by an elaborate arrangement of screens, to make this atiraction iust evident to an audience. $-C$. V. B. were plane, the whole movement of the light would be only about 8 inches, but the mirror is convex, and this magnifies the motion nearly eight times. At the present moment the attracting weights are in one extreme position, and the line of light is quiet. I will now move them to the other position, and you will see the result-the light slowly begins to move, and slowly increases in movement. In forty seconds it will have acquired its highest velocity, and in forty more it will have stopped at 5 feet $8 \frac{1}{2}$ inches from the starting-point, after which it will slowly move back again, oscillating about its new position of rest.

It is not possible at this hour to enter into any calculations; I will only say that the motion you have seen is the effect of a force of less than one ten-millionth of the weight of a grain, and that with this apparatus I can detect a force two thousand times smaller still. There would be no difficulty even in showing the attraction between two No. 5 shot.

And now, in conclusion, I would only say that if there is anything that is good in the experiments to which I have this evening directed your attention, experiments conducted largely with sticks, and string, and straw and sealing-wax, I may perhaps be pardoned if I express my conviction that in these days we are too apt to depart from the simple ways of our fathers, and, instead of following them, to fall down and worship the brazen image which the instrument-maker hath set up.

\section{A NEW SCHOOL OF ORIENTAL STUDIES.}

THE Imperial Institute has taken a most important step towards the organization of higher commercial education in London, by effecting an arrangement between University and King's Colleges for the establishment of a new School for Oriental Studies. The close connection between the mercantile interests of this country and of India, Turkey, China, South Africa, and other lands, renders it very desirable that travellers and traders should have full facilities for acquiring, not only a knowledge of the languages of those countries, but also some acquaintance with the habits and customs of the inhabitants. In France and Germany, we find that the wants of this class of students have been fully recognized by the State. The French School of Oriental Languages has been in existence over 100 years, and has recently been reconstructed at an annual expense, for maintenance alone, of $£ 6000$; and in 1887 a new school was opened in Berlin, as a special department of the University, which receives a subvention from the Government of over $£ 3000$ a year. In England, the economy to the nation of adequately supporting institutions for higher education is not yet understood, and consequently private effort has to step in and relieve the State of a duty which in other countries is discharged in no niggard spirit. The new School of Criental Studies promises to supply a distinct want. Instruction will be given in the principal Indian languages, in Persian, Burmese, Malay, Arabic, Turkish, Russian, Modern Greek, Chinese, Japanese, and Swaheli. The students will be taught not only to read and write, but also, as far as is possible, to speak those languages; and to this end the Committee contemplate the appointment of native readers and teachers of conversation. It has already been arranged that some of the Professors will preface their course's of linguistic teaching by lectures on the history, the physical and commercial geography, and the economic condition of the countries in which the various languages are spoken. It is hoped that by such means our mercantile and official classes may have the opportunity of acquainting themselves with the life and thought of the different Eastern peoples with whom they may be brought into communication.

The Imperial Institute is to be congratulated $\mathrm{n}$ h having succeeded in bringing into harmonious working the two London Colleges, to each of which has for many years 
been attached a staff of eminent Professors of Oriental languages. The Indian School of University College, and the Oriental Section of King's College, have both done useful work ; but, mainly from want of proper organization, the classes of many of the Professors have been but poorly attended, and several important modern languages a knowledge of which is now needed have not been included in the prospectus of either school. The Institute has effected an arrangement with the Colleges whereby the Indian and some allied tongues will continue to be taughe in Gower Street, whilst the other languages will be taught at King's College, Strand. This is perhaps the first instance of such an arrangement between the two Colleges having been brought about, and suggests the practical advantage of an extension of the system to other branches of learning. It is only by a proper organization of the higher instruction that London can secure the full advantages of University education, and it may be hoped that as soon as a teaching University can be established in London, the two Colleges and the Medical and Science Schools will be found to co-operate with one another, so as to supplement, without unduly interfering with, each other's field of work.

We should add that the new School of Oriental Studies, which will be opened in October next, is under the general management of a special Committee, which comprises among its mernbers Sir Francis Bell, Sir Charles Wilson, Sir Thomas Wade, Sir Frederic Goldsmid, and representatives of the governing bodies and teaching staffs of the two Colleges.

\section{NOTES.}

This year the French Association for the Advancement of Science will hold its annual meeting in Paris. The session will last from August 8 to 14. A great number of members are expected to attend the meeting, and it is hoped that many foreign men of science may also be present.

The International Congress which met in Paris in 1887 to make arrangements for the preparation of a photographic chart of the heavens expressed a wish that a similar Congress might meet for the discussion of questions relating to celestial photography in general. M. Janssen and Mr. Common were asked to take such steps as might be necessary for the attainment of this object; and afterwards, by a Ministerial decision at Paris, an organizing Committee, with M. Janssen as President, was appointed. The arrangements have now been completed, and the Congress will be held in Paris from August 22 to September 3. The aim of the Congress will be to determine the methods which are most suitable for each branch of celestial photography, and the means by which the results obtained by these methods can be most effectually published and preserved.

THE Botanical Society of France announces the following programme of the forthcoming Botanical Congress to be held in Paris :-Tuesday, August 20: opening sitting of the Congress at 2 p.m., at the hotel of the Horticultural Society, 84 Rue de Grenelle ; reception of foreign members at 8.30 p.m. Wednesday, August 2I : sitting at 9 a.m., devoted to the consideration of the first question, on the utility of an agreement between the different Botanical Societies and Museums, for the purpose of drawing up charts of the distribution of species and genera of plants on the globe ; and other communications, if time allows. Thursday, August 22: excursion in the neighbourhood of Paris. Friday, August 23: sitting at 9 a.m., devoted to the consideration of the second question, on the characters furnished by anatomy for classification ; and other communications, if time allows. In the afternoon $\mathrm{a}$ visit to the botanical collections and laboratories of the Museum of Natural History, and of the other large scientific establishments in Paris. Saturday, August 24 : sitting at 9 a.m., miscellaneous contributions. In the afternoon a visit to the Exhibition. Sunday, August 25: banquet to the foreign botanists. During the following week several botanical excursions will also be arranged. Special arrangements with regard to railway fares will be made in favour of botanists announcing their intention to be present to M. P. Maury, the Secretary to the Committee of Organization, 84 Rue de Grenelle, before July 25 .

THE following are subjects proposed for discussion at the International Zoological Congress, to be held in Paris (August 5-10) :-Adoption of rules on the nomenclature of organisms, and of an international scientific language; determination of regions the fauna of which calls for investigation; methods of investigation and procedure in preparation and preservation of animals; the use of embryology in classification; relations between living and fossil fauna. The Secretary's address is 32 Rue de Luxembourg.

AT the International Congress on Hygiene and Demography, also to be held during the Paris Exhibition, there will be discussed:-The administrative and medical regulations framed in different countries in the interests of health and of infantile life; removal and utilization of solid detritus in cities and the country; regulation and distribution of temperature in the dwelling; action of the soil on germs of disease; protection of watercourses and of ground water from pollution by factory refuse; sanitation of ports ; accidents through food-stuffs of animal origin containing poisonous alkaloids ; statistics of the causes of death in cities.

Some valuable reports were distributed among the members of the International Agricultural Congress, which finished its labours at Paris the other day. One of them relates to agricultural education. This report is signed by a dozen authors, among whom are MM. Tisserand, Prilleux, and Jamieson, the latter an Englishman.

THE sixty-second meeting of German Naturalists and Physicians will be held at Heidelberg from September 17 to 23. One whole day will be devoted to excursions in the neighbourhood, and on the evening of September 23 the Castle of Heidelberg will be brilliantly illuminated.

AT a meeting of the Council of Dundee University College, held on the 3 rd instant, Mr. J. Martin White announced that he had been authorized by Mr. John Bett, merchant, Rohallion, to offer a third of the amount required to found and establish a Chair of Physiology in connection with the Medical School of the College, provided the remaining two-thirds of the amount required be raised. It was mentioned that, to provide a fund adequate for the endowment of the Chair and the furnishing of suitable buildings and equipment, a sum of about $f \mathrm{r} 5, \infty 00$ would be necessary. The foundation of this Chair would enable the College to complete the first two years of a medical curriculum.

A CIRCULAR from Harvard College Observatory, dated June 26, states that the sum of fifty thousand dollars has been received by that Observatory from Miss C. W. Bruce, of New York, to be applied "to the construction of a photographic telescope having an objective of about 24 inches aperture with a focal length of about 1 I feet; . . . also to secure its use under favourable climatic conditions in such a way as will best advance astronomical science."

A statue of Paul Bert was unveiled at Auxerre on Sunday last. The ceremony was attended by the Annamite Envoys, and M. Spuller represented the French Government.

Dr. E. Heinricher has been appointed Professor of Botany and Director of the Botanical Garden at Innsbriick; and Dr. H. Ambronn, Professor of Botany at Leipzig. 